travel to areas with malaria is stated in the article. Many possible approaches to dissuading a determined traveler who already has firm plans and tickets in hand are conceivable. The most frequently successful strategy is a change of destination to one allowing a similar experience but without the malaria risk. A specialized travel medicine clinic (listings at www.istm.org and www.astmh.org) would have access to countryby-country malaria maps and would also be familiar with common and practical destinations. Many game parks in South Africa are outside the malaria zone, though the itinerary described in the vignette is by far the most popular. Delaying the trip by a year would involve exposing an infant to malaria, an equally risky situation, or separating mother and child by thousands of miles for a significant period. Despite our best efforts, pregnant women travel not infrequently to malaria zones, and we need to offer them information on the best possible prevention strategies.

David O. Freedman, M.D.

University of Alabama at Birmingham

Birmingham, AL 35294-2170

\title{
The FDA and Tobacco Regulation
}

TO THE EDITOR: The American Heart Association enthusiastically supports the editorial by Curfman et al. (Sept. 4 issue) ${ }^{1}$ on a bill that would grant authority to the Food and Drug Administration to regulate tobacco products. We believe that this legislation has several strengths; it would require full disclosure of the ingredients in tobacco products, reduce the burden of tobacco-related illnesses, and especially limit underage smoking. Each day, about 4000 people 12 to 17 years of age will try a cigarette for the first time, and an estimated 1140 persons in this age group become daily smokers. ${ }^{2}$ According to a U.S. Surgeon General's report, about $80 \%$ of people who use tobacco begin to do so before 18 years of age. ${ }^{3} \mathrm{~A}$ major curtailment of underage tobacco use may be the greatest potential public health benefit of this legislation. As the incoming president of the American Heart Association, I applaud the position of the Journal editors and join with them in expressing unequivocal support for this legislation.

Clyde Yancy, M.D.

American Heart Association

Dallas, TX 75231

1. Curfman GD, Morrissey S, Drazen JM. The FDA and tobacco regulation. N Engl J Med 2008;359:1056-7.

2. Office of Applied Studies. Results from the 2005 National Survey on Drug Use and Health: national findings. NSDUH series H-30. Rockville, MD: Substance Abuse and Mental Health Services Administration, 2006. (DHHS publication no. SMA 064194.)

3. National Center for Chronic Disease Prevention and Health Promotion, Office on Smoking and Health. Preventing tobacco use among young people. Washington, DC: Government Printing Office, 1994.

\section{Restless Legs Syndrome and Spinal Anesthesia}

TO THE EDITOR: The restless legs syndrome (RLS) is a common sensorimotor disorder of unknown cause affecting approximately $10 \%$ of the population. ${ }^{1}$ One uncontrolled study showed that spinal anesthesia caused postoperative RLS. ${ }^{2}$ We conducted a prospective study to determine whether the occurrence of postoperative RLS was associated with the type of anesthesia.

Patients scheduled for surgery and general or spinal anesthesia were recruited from our hospi- tal's lists of patients undergoing elective surgery (Table 1). Using a standardized questionnaire (see the Supplementary Appendix, available with the full text of this letter at www.nejm.org), one of us interviewed patients - on admission and at 1 and 4 weeks postoperatively - about symptoms, including diagnostic criteria for RLS ${ }^{3}$ and symptoms of depression and daytime sleepiness. The questions regarding RLS symptoms were interspersed among other questions to mask 


\begin{tabular}{|c|c|c|c|}
\hline Characteristic & $\begin{array}{c}\text { Spinal } \\
\text { Anesthesia } \\
(\mathrm{N}=147)\end{array}$ & $\begin{array}{c}\text { General } \\
\text { Anesthesia } \\
(\mathrm{N}=212)\end{array}$ & P Value \\
\hline Sex - no. M/no. F & $84 / 63$ & $121 / 91$ & 0.96 \\
\hline Age $-y r$ & $61.6 \pm 12.8$ & $44.6 \pm 16.7$ & $<0.001$ \\
\hline Weight - kg & $78.9 \pm 16.7$ & $82.2 \pm 19.6$ & 0.10 \\
\hline \multicolumn{4}{|l|}{ Procedure - no. of patients } \\
\hline Orthopedic & 85 & 46 & \\
\hline Otorhinolaryngeal & 0 & 161 & \\
\hline Urologic & 59 & 0 & \\
\hline Ophthalmologic & 0 & 4 & \\
\hline Inguinal & 3 & 0 & \\
\hline Neurosurgical & 0 & 1 & \\
\hline Duration of surgery - $\min$ & $56 \pm 34$ & $122 \pm 75$ & $<0.001$ \\
\hline Postoperative nausea and vomiting - no. of patients & 1 & 9 & 0.052 \\
\hline Preexisting RLS — total no. of patients (no. M/no. F) (\%) & $16(5 / 11)(10.9)$ & $16(5 / 11)(7.5)$ & 0.28 \\
\hline \multicolumn{4}{|l|}{ Age group — total no. of patients (no. with RLS) } \\
\hline $18-20 \mathrm{yr}$ & $0(0)$ & $14(0)$ & \\
\hline $21-30 \mathrm{yr}$ & $2(0)$ & $39(1)$ & \\
\hline $31-40 \mathrm{yr}$ & $7(0)$ & $40(2)$ & \\
\hline $41-50 \mathrm{yr}$ & $19(2)$ & $38(4)$ & \\
\hline $51-60 \mathrm{yr}$ & $37(4)$ & $35(4)$ & \\
\hline $61-70 \mathrm{yr}$ & $45(5)$ & $36(4)$ & \\
\hline $71-80 \mathrm{yr}$ & $29(4)$ & $8(1)$ & \\
\hline $81-90 \mathrm{yr}$ & $8(1)$ & $2(0)$ & \\
\hline New-onset postoperative RLS — no. of patients & 0 & 0 & \\
\hline Exacerbation of preexisting RLS symptoms - no. of patients & 0 & 0 & \\
\hline $\begin{array}{l}\text { Percent risk of new-onset RLS after anesthesia - } 99 \% \text { confidence } \\
\text { interval }\end{array}$ & $0-4.0 \%$ & $0-2.7 \%$ & 0.94 \\
\hline
\end{tabular}

* Plus-minus values are means \pm SD. Patients were 18 to 90 years of age and were randomly selected from the surgical lists of elective procedures. Patients who were taking medication for chronic pain were excluded. The choice of anesthesia was made according to usual clinical practice. None of the female patients were pregnant. Spinal anesthesia consisted of $0.5 \%$ hyperbaric bupivacaine administered at the L2-L3 or L3-L4 vertebral interspace with a 25 - or 27-gauge pencil-point needle. General anesthesia consisted of propofol and an opioid (remifentanil, fentanyl, or alfentanil). Postoperative analgesia consisted of rectal diclofenac and intravenous acetaminophen supplemented with opioids, if required. $\mathrm{P}$ values were calculated with the use of the t-test, Fisher's exact test, or the chi-square test, according to the type of data.

the true objective of the survey, in order to avoid the response bias that often occurs with repeated questioning.

Thirty-two patients (8.9\%) had preexisting RLS. No patients had new RLS postoperatively or worsening of preexisting symptoms. The $99 \%$ confidence interval for the risk of postoperative onset or worsening of RLS was 0 to $1.3 \%$ for the total sample and 0 to $1.6 \%$ for new-onset RLS. The $99 \%$ confidence interval for new-onset RLS was 0 to $4.0 \%$ for patients who had spinal anes- thesia and 0 to $2.7 \%$ for patients who had general anesthesia $(\mathrm{P}=0.94)$.

The prevalence of RLS and the sex and age distributions of patients with RLS in our sample were consistent with those in other published reports. ${ }^{4}$ Our data do not support the hypothesis that spinal anesthesia induces RLS. Our results are not consistent with a previous study by Högl et al., which showed that RLS developed in $8 \%$ of patients treated with spinal anesthesia. ${ }^{2}$ The discrepancy between those findings and ours may 
be explained by limitations of this earlier study, ${ }^{2}$ which did not include a preoperative interview to assess patients for preexisting RLS. Differences in the study populations also may have contributed to the discrepancy. For example, $36 \%$ of the patients in the study by Högl et al. had a cesarean section with spinal anesthesia, which is associated with a high rate of postoperative nausea and vomiting; at the time of the study, postoperative nausea and vomiting were often treated with drugs, such as metoclopramide and droperidol, that are known to cause akathisia, a disorder that can be confused with RLS. ${ }^{5}$ We conclude that neither spinal anesthesia nor general anesthesia with propofol and an opioid induces or exacerbates the symptoms of RLS.

Thomas A. Crozier, M.D., Ph.D. Desiree Karimdadian, M.D.

Svenja Happe, M.D.

University of Göttingen Medical School

37075 Göttingen, Germany

tcrozie@gwdg.de
Dr. Crozier reports receiving lecture fees from Bristol-Myers Squibb; and Dr. Happe, lecture fees from Boehringer Ingelheim, GlaxoSmithKline, UCB, Roche, Pfizer, Cephalon, and SanofiAventis. No other potential conflict of interest relevant to this letter was reported.

1. Earley CJ. Restless legs syndrome. N Engl J Med 2003;348: 2103-9.

2. Högl B, Frauscher B, Seppi K, Ulmer H, Poewe W. Transient restless legs syndrome after spinal anesthesia: a prospective study. Neurology 2002;59:1705-7.

3. Allen RP, Picchietti D, Hening WA, Trenkwalder C, Walters AS, Montplaisi J. Restless legs syndrome: diagnostic criteria, special considerations, and epidemiology: a report from the restless legs syndrome diagnosis and epidemiology workshop at the National Institutes of Health. Sleep Med 2003;4:101-19.

4. Garcia-Borreguero D, Egatz R, Winkelmann J, Berger K. Epidemiology of restless legs syndrome: the current status. Sleep Med Rev 2006;10:153-67.

5. Walters AS, Hening W, Rubinstein M, Chokroverty S. A clinical and polysomnographic comparison of neuroleptic-induced akathisia and the idiopathic restless legs syndrome. Sleep 1991; 14:339-45.

Correspondence Copyright (c) 2008 Massachusetts Medical Society.

INSTRUCTIONS FOR LETTERS TO THE EDITOR

Letters to the Editor are considered for publication, subject to editing and abridgment, provided they do not contain material that has been submitted or published elsewhere. Please note the following: $\cdot$ Letters in reference to a Journal article must not exceed 175 words (excluding references) and must be received within 3 weeks after publication of the article. Letters not related to a Journal article must not exceed 400 words. All letters must be submitted over the Internet at http://authors.nejm.org. - A letter can have no more than five references and one figure or table. A letter can be signed by no more than three authors. -Financial associations or other possible conflicts of interest must be disclosed. (Such disclosures will be published with the letters. For authors of Journal articles who are responding to letters, this information appears in the published articles.) -Include your full mailing address, telephone number, fax number, and e-mail address with your letter.

Our Web site: http://authors.nejm.org

We cannot acknowledge receipt of your letter, but we will notify you when we have made a decision about publication. Letters that do not adhere to these instructions will not be considered. Rejected letters and figures will not be returned. We are unable to provide prepublication proofs. Submission of a letter constitutes permission for the Massachusetts Medical Society, its licensees, and its assignees to use it in the Journal's various print and electronic publications and in collections, revisions, and any other form or medium. 